\title{
Retórica aristotélica y semiótica: convergencias
}

\author{
ESTHERLYDIA PAGLIALUNGA \\ Universidad de Los Andes \\ Venezuela
}

\begin{abstract}
RESUMO: Partindo de uma via dupla de indagação, representada respectivamente pela retórica aristotélica e pela semiótica greimasiana, percebemos uma série de convergências que nos autorizam a revalorizar a obra aristotélica. Entre as convergências mais notáveis está a coincidência entre a concepção das denominadas provas patéticas ou "paixões" e a estrutura modal da manipulação da semiótica de Greimas. No presente artigo concentramo-nos em outros aspectos da convergência: 1) o estabelecimento da sintaxe actancial da enunciação, ou seja, da existência de três actantes: um Enunciador, encarregado do fazer persuasivo; um Enunciatário,sujeito do fazer interpretativo, e um actante-objeto, sobre quem repousa a crença; 2) a competência de ambos os sujeitos e a relação de credibilidade e "credulidade" estabelecida entre eles. $\mathrm{Na}$ competência do sujeito crível observa-se a necessidade de "ocultar" o domínio técnico da palavra, para não gerar desconfiança.
\end{abstract}

PALAVRAS-CHAVE: Retórica aristotélica, semiótica greimasiana, sintaxe actancial da enunciação.

\section{Una doble vía de indagación}

La presente comunicación intenta mostrar determinadas conclusiones surgidas de dos vías simultáneas de indagación dentro de las cuales he conducido mis trabajos de investigación.

La primera está circunscrita al ámbito de la retórica clásica, y se apoya en la convicción de la necesidad de situar el análisis e interpretación de los textos en prosa producidos en la antigüedad en la perspectiva de la teoría y crítica literaria en las cuales están fundados. Teniendo en cuenta que la elaboración de una teoría y crítica sobre la prosa literaria comienza a plasmarse en Grecia a partir de la sofística y encuentra uno de sus hitos fundamentales en la obra de Aristóteles, es en ella que se ha centrado la búsqueda de los fundamentos teóricos sobre el discurso en prosa. Considero que los presupuestos de la Retórica de Aristóteles merecen una indagación renovada que los despoje de la carga que una tradición posterior arrojó sobre ellos, haciendo perder de vista lo fundamental. Entre ellos se ubica, evidentemente, el excesivo desarrollo de la elocutio, en desmedro de las otras partes rhetoricae, así como el „furor taxonómico“- para emplear la designación de Barthes ( Barthes, 1974, p. 73) - en el tratamiento de las figuras.

La segunda vía está determinada simultáneamente por una exigencia y decisión teóricometodológicas. La exigencia de confrontar los presupuestos clásicos con las teorías actuales del discurso- como una parte de una más amplia renovación de planteos que juzgo ineludible en 
nuestra disciplina. La decisión de situarme en el marco de los postulados de la Escuela Semiótica de París, si por un lado constituye una suerte de pasión personal, no está despojada, por otro, de la necesaria convalidación Existen importantes trabajos sobre diferentes aspectos de la cultura clásica enfocados desde esta perpectiva ${ }^{1}$, y en lo que respecta al campo de la retórica ya el opúsculo de Barthes arriba citado- en su apretada síntesis - avanzaba consideraciones por demás significativas, así como es bien conocida la obra del Grupo de Lieja. Además, a partir del año 1990, en la Universidad de Los Andes, el Grupo de Investigaciones Sociolingüísticas, del que formo parte, está dedicado a una rama más reciente dentro de esta teoría: la Sociosemiótica en cuyo marco se inscribe la posibilidad del estudio del discurso político. En este aspecto deben destacarse los aportes de Eric Landowski ${ }^{2}$ que juzgo de gran aplicabilidad para los objetivos por mí planteados.

Situada en esta doble trayectoria realicé el análisis del móa $\theta$ os en la Retórica de Aristóteles, un trabajo de incipiente andamiaje semiótico ${ }^{3}$, cuyos avances hemos continuado a la luz de la última obra sobre este tema de A. Greimas y J. Fontanille Sémiotique des passions.

\section{Retórica aristotélica y semiótica: Convergencias}

Con un entusiasmo que intento acompañar de rigor y dominio teórico, la persistencia en ambas líneas de investigación me ha conducido al menos a la certidumbre de que la aproximación no es azarosa o meramente subjetiva. Pretendo con esto afirmar que he ido detectando lo que podría designar como una coincidencia de planteos teóricos, una surte de semiótica avant la lettre en la Retórica de Aristóteles.

Señalaré tres de los aspectos en los que baso mi hipótesis, para referirme más específicamente al tercero como núcleo de este artículo:

1) la postulación de una sintaxis actancial de la enunciación;

2) la teoría de la manipulación que subyace todo el tratamiento del má $\theta$ os en el libro II de la Retórica;

3) la presuposición de un contrato fiduciario entre los actantes de la enunciación.

\section{El metatérmino "discurso"}

Una objeción más que razonable podría plantearse antes de continuar: ¿no están identificándose arbitrariamente los términos utilizados en semiótica y en la Retórica? De hecho, discurso en la teoría greimasiana (Greimas,1979, p.102) es un metatérmino omnipresente, que apunta, al menos a tres conceptos:

a) discurso identificado con proceso semiótico: la totalidad de hechos semióticos situados sobre el eje sintagmático del lenguaje pertenecen a la teoría del discurso. En este marco, discurso y texto son sinónimos.

b) Discurso identificado con enunciado es la unidad objeto del análisis semiótico y constituye una totalidad significante.

c) Es asimismo aquello que la enunciación enuncia: la puesta en discurso o discursivización

Ahora bien, la polisemia de la palabra $\lambda o ́$ yo $\varsigma^{4}$ - utilizada en los tratados de retórica para referirse al discurso en prosa- apunta a otros campos y no puede asimilarse simplemente al metatérmino discurso de la semiótica.

En primer lugar, si toda forma literaria- así como otros conjuntos significantes- puede ser englobada, desde el punto de vista semiótico, bajo la denominación de "discurso" o "texto", en la teoría aristotélica- se distinguen dos tipos de producciones: de una - constituídas por los textos "en verso", se ocupa la Poética; de la otra, la Retórica, que si bien en principio se refiere al 
discurso forense, deliberativo o panegírico, llega a abarcar todo tipo de texto en prosa. Tal es el

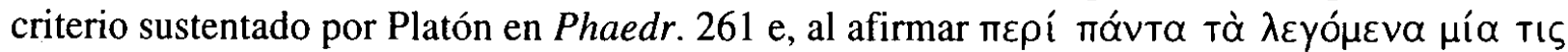
$\tau \dot{\varepsilon} \chi \vee \eta$ (si hay un arte de la palabra comprende toda clase de discursos), que se advierte también en el pasaje de la Retórica de Aristóteles 1391b 18, en el cual incluye otro tipo de textos persuasivos, tales como la exposición o discusión teórica de un saber. Asimismo, en la Poética 1447 b se apunta a una diferencia entre dos artes literarias, que radicaría en el hecho de que una usa la forma métrica y la otra no: esta estaría representada por la historia, la oratoria, los diálogos en prosa ${ }^{5}$.

La progresiva invasión de las categorías retóricas en el campo de la reflexión y crítica sobre la poesía, irá produciendo un desdibujamiento de fronteras cuya consecuencia más relevante es la validez de determinados criterios de análisis y crítica en relación con ambos tipos de textos. Remitiéndonos a la diferenciación establecida por Lausberg (Lausberg, 1966, I, p 88.), entre el officium poetae( la mímesis) y el officium oratoris (la persuasión), lo más significativo de esta asimilación está representado precisamente por el efecto persuasivo que se traslada a la función mimética.

Hechas estas precisiones, entiendo que pueden equipararse ambos metatérminos en lo que respecta tanto al discurso entendido como enunciado, cuanto a los mecanismos de puesta en discurso o discursivización.

\section{La retórica y el hacer persuasivo}

Es oportuno destacar, como lo advierte Atkins (Atkins, 1961, I, p. 6) que el nacimiento de una teoría del discurso no constituye un campo autónomo sino que forma parte de la indagación filosófica y, más específicamente de las llamadas ,artes políticas“. Por eso es imposible separar los planteos sobre el estilo, composición o géneros literarios de los problemas ontológicos y gnoseológicos, como de los relativos a la idea del poder, a los medios para acceder a él, a la concepción de la sociedad y del Estado, o a las consideraciones acerca de las estructuras más eficaces para lograr un desenvolvimiento más pleno de la persona humana. Como es bien sabido, los sofistas se van a constituir en el tipo de maestros necesarios en un momento históricopolítico concreto: la democracia griega, que exige tanto la formación del ciudadano para su participación en los asuntos públicos, como la de aquellos que aspiran a formar parte de la clase dirigente, para lo cual deben poseer una capacidad de persuasión de las mayorías.

Esta formación incluye una serie de contenidos éticos y políticos, pero asimismo las artes o técnicas que garantizan un empleo más eficaz de la palabra, es decir, la retórica.

No puede omitirse, en consecuencia, una restricción: el hecho de que, como señala Greimas ( Greimas, Courtés, 1979, p.317), la retórica se ocupa sólo de un tipo de discursos: los discursos persuasivos, o me atrevería a precisar, sólo concibe el discurso como un hacer persuasivo: $\dot{\eta}$

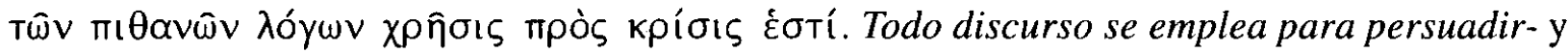
este es el pasaje en que el término se amplía para abarcar otro tipo de textos-, ya sea a un oponente individual, ya a uno colectivo, ya a una teoría.

Por ello, el denominador común de todo intento de definición de la retórica, y con ello, de la finalidad u objetivo del discurso, está representado por la concepción de la relación que este hacer-el persuadir-implica.

\section{Platón: la relación entre los actantes de la enunciación}

En el proceso de elaboración de una teoría del discurso, las reflexiones de Platón constituyen, obviamente, un hito fundamental. La crítica de Platón a la retórica nos permite 
circunscribir uno de los principales enfoques dentro de los cuales puede situarse el análisis del discurso. Me refiero a la posibilidad del discurso de transmitir un saber verdadero y a los criterios de legimitización de ese saber. Si bien en el Gorgias la crítica platónica ha sido extremadamente severa, al afirmar que la pretendida capacidad de los rhetores sólo consiste en producir falsas certezas u opiniones, frente a los ignorantes, en lugar de conducirlos a la conjunción con un verdadero saber, en el Fedro, sus postulados adquieren una perspectiva más positiva. De los principios enunciados en esta obra en relación con la capacidad de hablar y escribir bien y, por ende de lograr la persuasión, interesa particularmente lo que se refiere a los actantes de la enunciación. No se quiere decir que las consideraciones anteriores no tuvieran presente la estructura de la comunicación, sino que en el pasaje de Fedro a que aludimos la relación entre los dos protagonistas de la misma se formula de manera más explícita.

En efecto, en 270 b sigs., Platón advierte que unos discursos producen persuasión y otros no. Ello proviene del hecho de que el que habla (o escribe)- que en adelante llamaremos Enunciador-debe tener en cuenta frente a quién se encuentra y sólo un acabado conocimiento de la naturaleza humana le permitirá discernir el tipo de discurso que corresponde a esta clase de hombre. Ese conocimiento atañe a tres aspectos : el ser, el hacer, el padecer. Por supuesto, el estudio de la naturaleza humana está sujeto u orientado a la exigencia platónica de comunicarle la convicción y excelencia que es mejor para ella. Sin embargo, es evidente que se delinea la estructura de la comunicación y la relación entre los actantes de la misma.

\section{La sintaxis actancial de la enunciación}

Esta relación sostiene todas las reflexiones de Aristóteles, pues el punto de partida de su Retórica consiste en establecer los elementos constitutivos del discurso:

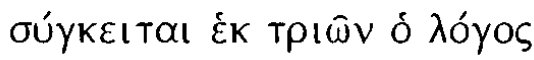

1) el hablante; 2) aquello de lo cual se habla, y 3 ) el oyente hacia quien se dirige el objetivo o finalidad del discurso.

Pero más ilustrativo aún acerca del hacer propio de cada uno de estos actantes es el

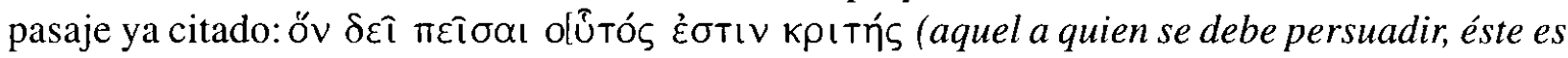
un juez: $I I, 18,1)$ : la finalidad del discurso persuasivo es la sanción o juicio epistémico del Enunciatario.

Esto equivale, en términos semióticos, a afirmar que en la problemática de la comunicación se encuentran implicados tres actantes:

a) el objeto sobre el cual reposa la creencia o duda;

b) un primer sujeto-Enunciador- encargado de un hacer persuasivo: el hacer-creer, o adoptando el metatérmino de Landoswki ( Landowski, 1989, p. 210 ) dotado de credibilidad.

c) Un Enunciatario, sujeto de un hacer interpretativo, que concluirá en un juicio epistémico: creer-verdad los enunciados sometidos por el Enunciador, dicho con Landowski, capaz de credulidad.

En este punto he creído pertinente utilizar los avances realizados por E. Landowski y recurrir a la distinción planteada entre las dimensiones argumentativa y persuasiva. De hecho, la importancia atribuída en la retórica al desarrollo de la prueba parecería obligar a situarse en una teoría de la argumentación, que la semiótica no ha desarrollado. Sin embargo ese vacío ha sido llenado por la problemática de la puesta en escena del razonamiento y por la reflexión sobre los procedimientos de persuasión. El mencionado autor advierte que la convicción de que no siempre es necesario justificarse racionalmente para ser creído, ni basta probar lo dicho para hacerse creer, llevan a admitir la existencia de dos niveles de funcionamiento del creer: 1) creer lo que dice alguien ; 2) creer a aquel que dice algo. 
Aunque parezca obvio, es oportuno recordar el valor semántico del término empleado por la retórica para designar los medios probatorios míoTı $\zeta$ es en principio, confianza, y luego medio de inspirar confianza, y por tanto, prueba. Por ello, esas pruebas, pueden construirse dentro del

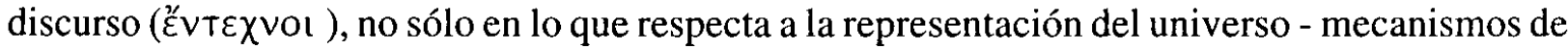
puesta en juego para crear ilusiones referenciales - que tienden a la producción de simulacros encargados de garantizar la adecuación de los discursos y los universos de referencia de los cuales se presentan como „representación“- sino también ilusiones enunciativas - que apelan a la competencia de los sujetos de la comunicación.

La ilusión enunciativa, garantía del creer, resulta de la superposición de niveles provenientes de que las partes que intervienen en el acto de la enunciación son simultáneamente las figuras actanciales del discurso enunciado encargadas de cumplir diversos programas narrativos. No hay que olvidar que la elaboración de la retórica gira, principalmente, en torno al discurso político, donde esta superposición de niveles está siempre presente: el Enunciador es, en el plano narrativo, Sujeto de un programa narrativo; el Enunciatario, Destinador- Juez (крıти́s) de la sanción.

\section{La competencia de ambos sujetos: credibilidad y credulidad}

El análisis de la competencia del sujeto creíble muestra, a mi parecer, una notable coincidencia con las denominadas pruebas éticas en la Retórica. En efecto, cuando Aristóteles señala que el discurso debe ser enunciado de tal manera que haga al hablante (Enunciador) digno de confianza åłıı ıтı бTós (I,2,4), y más adelante que esto se logra si se muestra dotado de

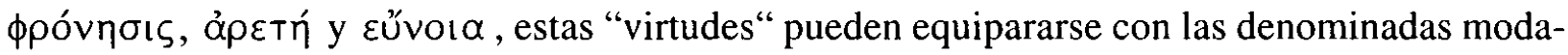
lidades actualizantes ( saber/poder) y virtualizantes (querer/deber). Aristóteles advierte claramente que no basta que alguien esté provisto del "saber adecuado", si no está bien dispuesto hacia los oyentes ( Enunciatario- Destinatario) o está desprovisto de ,honestidad"(deber-hacer).

Considero muy significativa en este aspecto la observación de Landowski en relación a que mostar un excesivo dominio "técnico" puede hacer perder credibilidad. De hecho, todo el bagaje de la competencia en el orden del saber, dentro de la Retórica, está sujeto a la posibilidad de re-conocimiento por parte del Enunciatario, es decir, a la integración del conocimiento en su universo cognoscitivo ${ }^{6}$. Como ya se ha indicado ese saber-hacer político incluye en su dominio técnico, el saber-hablar. Y entonces surge la paradoja que recorre gran parte de la tradición retórica: hay que hablar bien para convencer, pero una excesiva competencia en este orden engendra desconfianza. Creo que podría designarse este topos de la retórica con las palabras que Salustio en su Bellum Iugurthinum 85,31, pone en boca de Mario en su discurso ante la asamblea popular: Non sunt composita verba mea; parvi id facio.

De hecho, el carácter polémico del contexto en el cual tienen lugar los programas de las partes involucradas, en el cual la divergencia no sólo es posible sino garante del "libre juego democrático", funda una legítima desconfianza entre los sujetos. Si como dice Landowski (Landowski, 1989, p. 212), ,las sociedades se esfuerzan por ritualizar minuciosamente los procedimientos de encuentro", podemos afirmar que la retórica aristotélica abre camino a uno de esos ,estereotipos expresivos que se fundan en la doxa del grupo social“" . En efecto, si intentamos indagar que hay detrás del denominado principio de ocultamiento del arte ${ }^{7}$, enunciado en la Retórica III, 2, 4-5, pienso que la respuesta puede hallarse descubriendo cuáles son las relaciones actanciales que se postulan entre los sujetos. El pasaje es el siguiente: 
conviene que, al hacerlo, quede oculto y no parezca que se habla elaboradamente, sino con naturalidad, pues esto genera convicción, aquello, no.

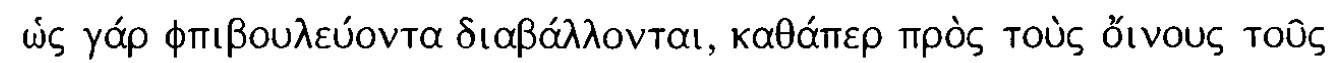
$\mu \varepsilon \mu \mathrm{l} \gamma \mu \dot{\varepsilon} \vee$ ou

pues se desconfía del que así "conspira", como de los vinos mezclados.

Si denominamos $S^{1}$ y $S^{2}$ a los sujetos involucrados, $S^{2}$ se presenta como un Sujeto cuyo Destinador no es $S^{1}$-lo que aseguraría la confianza- sino que se halla ligado a un Antidestinador, recubierto por la figura lexemática $\dot{\pi} \iota ß o u \lambda \varepsilon u ́ \omega$ ( tener una actitud hostil, conspirar contra), que

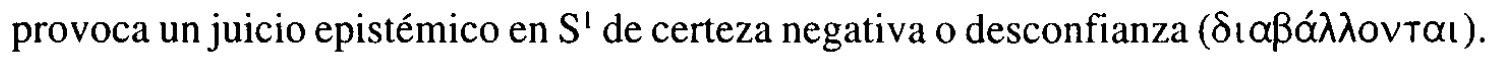

Teniendo en cuenta que tanto en este pasaje como en varios otros de la retórica, se condena el empleo de una $\lambda \hat{\varepsilon} \xi ı \varsigma$ poética, que es por tanto equiparada a lo artificial frente a lo natural, nos hallaríamos en el dominio de las connotaciones sociales, en este caso de aquellas que establecen el modo y grado de veredicción que una sociedad atribuye a los discursos. La oposición ficción/realidad, y por consiguiente, la atribución del estatuto de verdad- en lo que atañe al discurso objeto de la retórica- reside en no confundirse con el discurso poético.

\section{Notas}

1 - De especial interés resulta por su tratamiento de „Enunciados de la enunciación y sus sujetos en la antigua Grecia", la obra de Claude Calame Le recit en Grèce ancienne, Paris, Klincksieck, 1986.

2 - He utilizado particularmente La societé reflechie, en aquellos capítulos cuya confrontación con la retórica ha resultado más productiva para el propósito de este artículo, como son los VIII, IX, y X.

3 - Este trabajo El pudor en la novela griega, aún inédito, consistió en un intento de establecer los códigos sociales normativos que subyacen las relaciones entre los sujetos, tomando en cuenta la competencia modal.

4 - Relato, discurso, enunciado, argumento, razón, etc; cf. las ocurrencias del vocablo recopiladas por Wartelle para la Poética (Wartelle, 1985, p.91-92 ) y la Retórica (Wartelle, 1982, p. 241 244).

5 - Utilizamos la interpretación de este pasaje hecha por Cappelletti (Cappelletti, 1990,p.40)

6 - Relacionado con este tema, he publicado un artículo sobre el estatuto cognoscitivo del Enunciatario- Juez de la sanción epistémica (El estatuto cognoscitivo del oyente-especta$d o r$,) que es válido para mostar otra línea de convergencia entre retórica y semiótica: la necesidad de vincular el "conocer" al mundo del "creer" del Destinatario.

7 - Seguimos la denominación de Atkins (Atkins, 1961, I, p.149) al referirse a este principio que tendrá tan larga perduración en la teoría y crítica literarias.

\section{Referencias Bibliográficas}

ARISTOTLE, The "art" of Rhetoric. Trans. by John H. Freese. Cambridge: London, 1982. Loeb Clas.Lib..

ARISTOTLE, Poetics. Trans. by W.Hamilton Fyfe. Cambridge: London, 1960. Loeb Clas.Lib.. 
ATKINS, J.W. H. Literary criticism in Antiquity. Gloucester Mass.: Peter Smith, 1961.

BARTHES, R. La antigua retórica. (trad. Beatriz Dorriots ) Buenos Aires: Ed. Tiempo Contemporáneo, 1974.

CAPPELlETTI, A. Aristóteles. Poética. Caracas: Monte Avila Editores, 1990.

GREIMAS, A.J., Courtés, J. Sémiotique. Dictionnaire raisonné de la théorie du langage. Paris: Hachette, 1979.

GREIMAS, A.J.,Du sens II. Essais sémiotiques. Paris: Ed. Du Seuil, 1983.

LANDOWSKI, E., La société reflechie. Paris: Ed. De Seuil, 1989.

LAUSBERG, H. , Manual de Retórica literaria (Trad. de José Pérez Riesco). Madrid: Gredos, 1966.

PLATO, Gorgias. Trans. by W.R.M. Lamb. Cambridge: London, 1953. Loeb Clas.Lib..

PLATO, Phaedro. Trans. by Harold North Fowler. Cambridge: London, 1953. Loeb Clas.Lib..

WARTELLE, A., Lexique de la Poétique d'Aristote. Paris: Les Belles Lettres, 1985

WARTELLE, A., Lexique de la Rhétorique d'Aristote. Paris: Les Belles Lettres, 1982

PAGLIALUNGA, Esther L. Aristotelian rhetoric and semiotic: convergences. Classica, São Paulo, 7/8: 329-335, 1994/1995.

\begin{abstract}
Taking into account both Aristotelian rhetoric and Greimasian semiotics respectively, a series of convergences observed permit a revaluation of Aristotle's work. Among the outstanding convergences is the coincidence between the concept of the so called pathetic proofs or "passions" and the modal structure of manipulations in Greimas' semiotic. In this article we focus on other aspects of convergency: 1) the stablishment of the actantial syntax of the enunciation: i.e., the presence of three actors : an Enunciator, responsible for the persuasive doing; an Enunciater, the subject of the interpretative doing, and an actant-object on where the belief or doubt rests; 2) the competence of both subsjects and the relation of credibility and credulity established between them. In the competence of the credible subject, one notices that the concealment of art is necessary in order to avoid distrust.
\end{abstract}

KEY WORDS: Aristotelian rhetoric, Greimasian semiotics, actantial syntax of enunciations. 